\title{
The Advanced Technology Bus and the Evolution of Workplace Expertise
}

\author{
David W. Partain \\ MetropolitanAtlanta RapidTransitAuthority
}

Abstract

The purpose of this paper is to define and explore the immediate and long term effects and the resulting organizational dynamics of advancing technology on maintenance workplace expertise in transportation. In the past ten years the face of maintenance in the transportation workplace has completely changed as computerization has taken over the control of transmissions, engines, and bus/truck environmental systems and transformed them from "closed" stand alone components to an interdependent "open system" in a state of constant communication. The immediate future brings with it the advanced technology of the Intelligent Transportation System with its Geographic Information System, in-vehicle logic system, automated annunciation, signal prioritization, global positioning, and live audio and visual data links with a central control center.

This complexification of the transportation maintenance workplace is being compounded by the growing use of alternative fuels, and the resultant requirement for the maintainer to learn a new operational set of skills and competencies. This evolution of technology in transportation has caused a revolution in technical training for which the maintainers of transportation resources must reskill immediately to meet the demands of the technology invasion. The paper examines the need for an accelerated evolution of workplace expertise using a combination of motor skill and cognitive training competency based learning techniques to evolve the maintainer through the phases of basic operation, to systems expert, to system creator. 
This evolution is accomplished through the use of a four step implementation strategy which begins with the determination of training sources, the development of an effective resource investment strategy, the development of a model trained cadre, and concludes with the expansion of this model to improve the overall baseline of workplace expertise.

\section{Introduction}

The post-World War II diesel mechanics maintained their skills with little technological upgrade training for 40 years, and then, with the advent of engine and transmission electronic controls, the world changed. No longer could the test light be used to troubleshoot every electrical circuit on the bus. Diagnostic equipment evolved through the multi-meter, the vacuum tube volt meter, the digital multi-meter, the laptop computer, and the digital diagnostic analyzer (Hannum 1990). Today, with Programmable Logic Controller circuits, mechanics must still be wamed not use the test light, but they continue to do so, at considerable expense.

As a result of this nonstop integration of technology into our modern transit buses, and the resultant complexification of maintenance tasks (Casti 1994), the normal divisions between "manual " and "intellectual" labor are collapsing. As transit maintenance moves toward the mediation and control of work using automated tools and test equipment, a greater number of workers at all levels are being compelled to conceptualize work and troubleshoot problems using a very different group of competencies than before (Di Bello 1994). The foremost role and goal of technical training in the transit maintenance organization has become the development of mechanic "workplace expertise." Workplace expertise is both the productivity multiplier and road-call minimizer in our transit bus maintenance technical organization.

The problem of developing workplace expertise has been an issue of concern since the Industrial Revolution and the advent of Frederick W. Taylor and the "one best way" to do a job (Taylor 1911). Since 1900, the American workforce has been subjected to several conflicting methods of developing and maintaining workplace expertise. These methods ranged from "de-skilling" or compartmentalization of tasks that resulted in increased personnel requirements, to "re-skilling" or developing a higher number of skills in a fewer number of people (successfully implemented by 
the Israeli Air Force), to the promotion of highly skilled technical workers to the ranks of "foreman" (often done without investing training in the development of requisite management and interpersonal skills) (Partain 1994), to the advent of team directed maintenance, which, in itself, presupposes and requires an entire hierarchy of skills be present before team formation can begin and the desired results produced (Howard 1995).

It is becoming apparent that the classic on-the-job training (OJT) instructional method of task certification training is becoming ever more difficult to implement successfully with the acquisition of advanced technology in transit. It is one thing to teach the steps of rebuilding a diesel engine "by the book," and another to teach analytical methods for computer ladder logic. We have now evolved to a workertechnology interface that must encompass two distinct forms of training activity with very different cognitive consequences. These forms are "constructive activity systems," which specify the goals to be accomplished but leave the means unspecified, and "procedural activities" which, like task-oriented OJT, specify both the goal and the means to attain a goal or complete a task (Di Bello and Glick 1993).

It has become essential to define the environment in which learning is to take place; however, much development of workplace expertise has been done without the essential definitions of "What does the organization want the level of expertise to be?", "What does technology require the level of expertise to be?" (Leibowitz 1986), and "What must the mechanic know to make any particular technology effective?" (Di Bello and Spenser 1994).

The level of expertise in the garage-centered bus maintenance organization is a hierarchy of building-block levels constituting a five-rung ladder composed of:

1) Basic understanding: This is the core concept to understanding. It is the minimum baseline of knowledge and competency that will allow the individual mechanic to operate the system, i.e., drive the bus, service the bus, activate the in-vehicle logic system, and document problems. These are the basic operator requirements of the service person which require only a premechanical knowledge of the bus. 
2) Basic operational capability: This is the development of the core knowledge essential to understanding how components on the bus work together as a system. Can the individual engage and operate the major systems on the bus (i.e., engine, transmission, heating and air conditioning systems, brake and air systems, and general electrical system) from a mechanical and systems operation point of view, including the reading and understanding of service manuals and the removal and replacement of components? These are the basic operations of the apprentice and basic mechanic. The advanced technology bus expands the horizons of basic operational capability to include automatic passenger counting, enunciators, global positioning system and the on-vehicle logic system (Reynolds and Paquet 1996).

3) Analytical troubleshooting capability: This reflects a higher level of understanding of the operation of specific components and systems and how they interact with other components and systems on the bus. Can the individual read and understand schematic and system diagrams? Can the individual use troubleshooting and fault isolation trees and ladder logic diagrams. Can the mechanic use test equipment and arrive at an accurate interpretation of test equipment readings? These are the operations of the experienced mechanic.

These first three rungs are dedicated to the maintenance of the system. The next two are dedicated to changing, improving, and/or innovating the system.

4) Capability to improve on the existing system: Can the mechanic analyze system operation to the point that deficiencies in the system can be identified and suggestions for improvement offered? This level requires the visualization of circuits and systems, in-depth knowledge of technical specifications, the accurate performance of corrective maintenance procedures on literally hundreds of repeat discrepancies. It requires intuition to guide the mechanic past the obvious and into the world of root cause analysis where the question is, "If the system should work because all of the components work, then why does the system continue to fail?" These are the skills and competencies of the "lead" mechanic (Newby and Stepich 1987). 
5) Capability to create a new system: Can the individual compare performance requirements to current system capabilities and devise new systems to optimize performance? Can the individual devise improvements for systems that have not yet failed (Field 1994)? These are the competencies of the "systems" mechanic (Chi et al. 1988). It is at this level that learning becomes very self-motivated and self-directed (Grow 1991, Mezirow 1985).

These rungs portray levels in a hierarchy that define the degree of expertise required to perform the task or process. To achieve required performance goals, technical training must be aimed at the right technical and/or information system, at the appropriate performance level, and applied at the right time (Carey 1985). For example, having technical training aimed at the operational performance level with workplace performance expectations at the troubleshooting performance level is a common but serious problem in that it produces a "remove and replace" mechanic. Most maintenance supervisors can relate to a workforce that hovers in that area between levels 2 and 3 .

Technical jobs (and technical training) in the workplace often have been different for those who troubleshoot and for those who operate technical systems (the bus). This is true in a typical Authority's Bus Services operation on the macro level where bus drivers (those who operate the technical system) and bus maintainers (those who troubleshoot the technical system) are separated. However, for one to understand the scope of the issue at the maintenance level, one must focus on the micro level of the garage maintenance organization, where it becomes apparent that within a maintenance workforce there is disparity in expertise and competency levels separating "troubleshooters" from the other mechanics. There tends to exist in the garage that small group of mechanics who have developed (either formally or informally) those clusters of skills that cause them to be called on more frequently to perform specific maintenance tasks on engine, transmission, and electrical systems.

This natural selection of skill development is typical in any technical maintenance organization. A longevity study of this phenomenon in the U.S. Air Force (USAF) revealed this same characteristic (DOD 1982). The USAF identified these mechanics as "Maintenance Heroes" and used them to demonstrate a desired perfor- 
mance standard. This study resulted in changes in USAF technical training that raised skill and capability standards to develop a greater pool of "Heroes" (increased workplace expertise).

The evolution in bus technology, which began in the mid 1980s with the move to electronic engine and transmission controls, began the dilution of post-World War II diesel mechanic workplace expertise that served transit and long-haul trucking well until the encroachment of automated systems into the diesel environment. This encroachment has continued to evolve to even more complex computer control and monitoring systems such as the integration of Programmable Logic Controllers (PLC) into bus systems. The investment in this evolution was and will continue to be an expensive and strategic business investment, especially in light of the commitment to adopt alternate fuel technologies. However, the fact is that the scope of technical training has not tended to evolve along with the new bus technology. This lag is now driving the (reactive) process of developing adequate technical workplace expertise (and technical training) to the top of Authority investment priorities for both funds, equipment, and personnel.

Artificial intelligence will continue to be increasingly built into our bus systems, as PLC's and other "in-vehicle logic (smart) systems" will be able to diagnose and troubleshoot themselves. For the mechanic, this causes an evolution from the maintenance of a purely mechanical system to the understanding, troubleshooting, and maintenance of a mechanical/intelligent hybrid system. The new systems rely on computer-assisted, problem-solving methods as opposed to previous maintenance methods of removing and replacing components sequentially in a system until the defective component is (finally) discovered. This evolution is compounded by the adoption of alternative fuel technology.

To develop the "smart systems" mechanic, a three-element technical training method has been proven successful:

1) The use of computer-based communications skills, by the use of a computer and specialized diagnostic software, to interface the mechanic with the mechanical systems host computer. This requires the mechanic to acquire new skills in computer operation and understanding. Troubleshooting the PLC 
system, for example, requires not only that the mechanic know how to connect and operate the computer, but also requires that the mechanic understand true/false ladder logic diagrams (Newby 1987).

2) The elevation of technical training content from component specific to total systems understanding to ensure adequate expertise to meet advanced technology maintenance and performance standards (Chi et al. 1988). This requires a long-term strategic investment in training and equipment and leads to the evolution from mechanic or instructor to internal technical consultant.

3) The development of a baseline "common core of experience" for the introduction of new systems and technologies (Rosow1988). This may require general re-skilling and upgrade of the workforce in the areas of basic electronics, systems operations, and computer diagnostic skills.

The advent of computerized bus technology has had a profound change on the basic mechanical principles practiced and applied at the garage level. Previously, the bus could be viewed as a series of closed systems, where the engine, the transmission, and the air conditioning and electrical systems could, to a great degree, be worked on by the mechanic as separate and independent mechanical/electrical entities. With the initial evolution to computerized engine and transmission systems, the separate mechanical entities combined. Troubleshooting became more sophisticated as did the test equipment. With the continued evolution of computerized bus electronic control systems, the four basic closed systems became connected and formed into an "open system" requiring far more sophisticated test equipment and troubleshooting abilities (Hannum 1990). As a result, the hierarchy of skills for a capable bus mechanic in the 1990 s has been completely restructured and redefined compared to those skills required of the bus mechanic in the 1980s (Business Week 1994). But, while millions of dollars have been and are being invested in procuring buses with the new technology, little has been invested in bringing increasingly obsolete 1980 s workplace expertise (Johnston 1987) in line with 1990s technology and skills requirements.

The increasing complexity of bus systems, compounded by the addition of the Intelligent Transportation Systems Initiative that incorporates geographic informa- 
tion and geographic positioning systems technology on the buses, as well as the introduction alternative fuel systems, will continue to drive the demand for (and complexity of) technical training (Rothwell 1994, Clark 1989). The requirement to provide a level of training that brings workplace expertise up to the current level of bus technology and complexity requires a strategic investment in training for productivity enhancement (Waldrop 1992).

Based on the documented results of technical training and productivity enhancement studies, targeted training for workplace expertise against a specific level of technology could raise the overall level of workplace expertise and resultant productivity of the workforce from 20 to 200 percent (Carnevale 1990).

With approximately 50 percent of bus maintenance work orders (MARTA 1996) oriented to the "electrical system" (not including programmed maintenance work orders), it is reasonable to project that the level of maintenance activity in this area will increase as our mechanics are forced to react to new electrical/electronic system problems being generated by the "open system" of newer buses. To compound this situation, add a highly-pressurized CNG fuel system or a very-low-temperature LNG fuel system with its own set of electronic system controls and monitoring devices, working in conjunction with its companion engine electronic control and monitoring system.

The corrective action to the current issue of electrical/electronic systems workplace expertise is reactive. These "lessons learned" must be applied to the training and preparation for the integration of open systems and alternative fuels technology on our urban transit buses. This training and preparation must be proactive (or predictive) as well as self-motivated and self-directed on the part of the individual mechanic (Mezirow 1985).

\section{Resolution Strategy}

It is easy to say, "Now that we have defined the problem, let's fix it." It is infinitely more difficult to bring the "fix" into reality, especially since training technology provides no "magic bullet" or 17-minute videotape to solve the problem. The answer is: We must do it with innovation. Innovation must be incorporated into 
a set of sequential steps (Quinn 1985) to systematically increase workplace expertise in open (computerized) systems and to develop a uniform base of electrical/electronic and alternative fuel knowledge in preparation for the arrival of new technology and fuel buses.

1) Identify who will solve the problem, and empower them to do so. Identifying the individuals or groups who will maintain the emerging technologies integrated into transit buses may require authorities to develop completely new career development paths for mechanics (Liebowitz et al.1986) as well as restructuring on-the-job training concepts to stress cognitive and analytical skills (Jacobs and Jones 1995).

2) Determine whether to do the job in-house or with external resources. Determine the resources required to implement the program and establish the methodology to secure the resources (Horne 1982).

3) Develop a small cadre of experts who will "lead the force" in resolving the problem. Select a core group of individuals who have the capability and motivation to learn new systems and methods. Use these individuals to provide worker input in the designing of the training program (Sonnefield 1986).

4) Identify and train the small number of mechanics in each garage that do systems work well. Using the training model developed in \#3 above, implement the training and begin to develop internal expertise (Feuer 1986).

5) Invest the time and resources for additional training for these mechanics. As new technologies are integrated into the bus, train the experienced cadre (\#4) first because of their cumulative background and expanded core of experience and competencies (Hewitt 1988).

6) Expand the training to other mechanics, thus enlarging the pool of workplace expertise in the mechanics of a bus as a system. This is the long-term fix to develop the skills and competencies required for the integration of new technologies. This phase implements competency-based learning for the long term (Davies 1973). 
The above methodology can also be applied to the development of workplace expertise in the area of CNG/LNG. The significant difference is that the formation of the training cadre and the major bulk of the training must be accomplished prior to the receipt of this technology. After-the-fact training on the bus $\mathrm{CNG}$ system is not acceptable, since there is little prior experience base or common core of experience on CNG/LNG propulsion, refueling, and electrical systems by transit bus mechanics.

Two priority issues for maintainers - electrical/electronic (open) systems workplace expertise and the development of alternative fuels workplace expertise-are progressing side by side and must be addressed simultaneously. While the short-term fix for electrical systems may be implemented within one year by realigning existing in-house resources or with the assistance of outside resources, the long-term fix is instituted through increased resources by the establishment of a professional instructor cadre or through cooperation with a local educational institution. The issues of alternative fuels, co-generation, and fuel cell technical training, however, are not so easily addressed. Given the limited technical core of experience in urban transit alternative fuel systems, this expertise will have to be secured and developed as an addition to current training capabilities and resources (Hamburg 1985).

In developing training systems for advanced technology, the training manager may wish to apply the T-5 concept of evaluating the capability of a new training program. Utilizing T-5, the following elements must be in place:

- Technical Data: Accurate maintenance technical manuals and schematic diagrams for training and troubleshooting.

- Test Equipment: Any test equipment peculiar to the new components or systems.

- Training Aids: High fidelity training aids using actual system components and capable of supporting fault insertion and fault isolation.

- Tools: Any special tool peculiar to the new components or systems.

- Training: Vendor/manufacturer training of the instructor cadre.

Absence of any of the " $T$ " elements may cause the training effort on the new technology to fail. 
As the transit industry experiences the near-term acquisition of more advanced technology buses, the strategic imperative to train mechanics and operators prior to new bus arrival becomes an obvious and sensitive issue. Given the lead time to secure and train such a resource, it appears that we are within the critical window to secure this resource so that training and manufacturer orientation can be completed and a training program be developed, in place, and in progress before technology leads training and the transit industry must play catch-up.

\section{References}

Business Week. 1994. Rethinking work. Business Week, October 17: 76-106.

Carey, M. L. 1985. How workers get their training. Washington D.C.: U.S. Department of Labor Statistics.

Carmevale, A.P., L. H. Gainer, and J. Villet. 1990. Training in America. San Francisco, CA: JosseyBass.

Casti, John L. 1994. Complexification: Explaining a paradoxical world through the science of surprise. NewYork: Harper Perennial.

Chi, M.T., R. Glaser, and M. J. Farr. 1988. The nature of expertise. Hillsdale, NJ: Earlbaum. Clark, Ruth C. 1989. Developing technical training. Phoenix, AZ: Buzzards Bay Press.

Davies, I. 1973. Competency-based learning: Technology, management, and design. New York: MoGrawHill.

Department of Defense 1982. Analysis of the characteristics of the aircraft maintenance technical workforce. Headquarters, United States Air Force (LEYY), The Pentagon, Washington, DC. Di Bello, L. 1994. Exploring the relationship between activity and expertise: A study of manufacturing workers learning MRP. Paper presented at the Second Naturalistic Decision Making Conference, June 13-15, 1994, Dayton, $\mathrm{OH}$.

Di Bello, L., and J.Glick. 1993. Technology and minds in an uncertain world. Paper presented at the 31st Annual Conference of the National Society for Performance and Instruction. April 12-16, Chicago, Il.

Di Bello, L. and Spencer, J.C. 1994. Constructive learning: A new approach to deploying technological systems into the workplace. NewYork: The CityUniversity of NewYork-Laboratory for Cognitive Studies.

Feuer, D. 1986. Growing your own technical experts. Training, July 23-26.

Field, Laurie 1994. Skills training for tomorrow's work force. San Diego: Pfeiffer \& Co. 
Grow, G. 1991. Teaching learners to be self-directed. Adult Education Quarterly41(3): 125-149. Hamburg, S.K. 1985. Training for new technology. NewYork: Work in America Institute.

Hannum, W. 1990. The application of emerging technology. Alexandria, VA:TheAmerican Society for Training and Development.

Hewitt, C. 1988. Education for the new technologies. London: Kogan Page.

Horne, R. 1982. Guide for implementing competency-based education in vocational programs. Blacksburg, VA: Virginia Dept. of Education, Division of Vocational and Adult Education.

Howard, Ann (ed). 1995. The changing nature of work. San Francisco: Jossey-Bass.

Jacobs, Ronald L., and Michael J. Jones. 1995. Structured on-the-job training: Unleashing employee expertise in the workplace. San Francisco: Berrett-Koehler.

Johnston, W. 1987. Workforce 2000: Work and workers for the twenty-first century. Indianapolis: Hudson Institute.

Leibowitz, Z.B., C. Farren, and B. L. Kaye. 1986. Designing career development systems. San Francisco: Jossey-Bass.

MARTA 1996. Annual analysis of maintenance indicators. Atlanta: Metropolitan Atlanta Rapid Transit Authority.

Mezirow, J. 1985. A critical theory of self-directed learning. In S. Brookfield (ed.), Self-directed learning: From theory to practice, New directions for adult and continuing education 25. San Francisco: Jossey-Bass.

Newby, T.J., and D.A. Stepich. 1987. Learning abstract concepts: The use of analogies as a mediational strategy. Journal of Instructional Development 10(2): 20-26.

Partain, D. 1994. Bus maintenance foreman training:A model for development and implementation.

Paper presented to the Metropolitan Atlanta Rapid Transit Authority, May 10, Atlanta.

Quinn, J.B. 1985. Managing innovation: Controlled chaos. Harvard Business Review, May/June: 73-84.

Reynolds, William J., and John F. Paquet. 1996. Can your bus be too smart for its chassis? Paper presented at the 1996 Bus Operations, Technology, and Management Conference of the American Public TransitAssociation, May 5-9, Kansas City, MO.

Rosow, J.M., and R. Zager, with Casner-Lotto and Associates. 1988. Training - the competitive edge: Introducing new technologies into the workplace. San Francisco: Jossey-Bass.

Rothwell, William J. 1994. Improving on-the-job training. San Francisco: Jossey-Bass.

Sonnenfield J.A., and C.A. Ingols. 1986. Working knowledge: Charting a new course for training. Organizational Dynamics, Autumn: 63-79. 
Taylor, F.W. 1911. The principles of scientific management. New York: Harper.

Waldrop, Mitchell M. 1992. Complexity: The emerging science at the edge of order and chaos. New York: Simon and Schuster.

\section{About the Author}

DAVID W.PARTaIN is the Director of Employee Development for the Metropolitan Atlanta Rapid Transit Authority, a past Fellow of the National Transit Institute, and a multiple recipient of the NTI Innovations in Training Award. 